\title{
El huracán que pasó por la ciudad de Veracruz y el puerto de San Juan de Ulúa, Nueva España 1552. La construcción de un "desastre" en la época virreinal
}

Paul César López Romero ${ }^{1}$

Recibido en febrero de 2016, aceptado en abril de 2016

\begin{abstract}
Resumen
Partiendo del análisis de las consecuencias del huracán que en 1552 azotó la ciudad de Veracruz y la isla de San Juan de Ulúa, el autor estudia las condiciones de vulnerabilidad de las ciudades de las colonias españolas, preguntándose cómo evaluar los daños y cuantificar sus efectos, y en general, cómo estudiar los desastres naturales desde las Ciencias Sociales. De este modo, se refiere a otros fenómenos naturales, como los ciclones y tormentas tropicales, de los cuales hay registros en las ciudades españolas. El estudio de las explicaciones a partir de la religiosidad de los pobladores de esos tiempos y su insistencia en dejar registro de todos los sucesos se analizan con detenimiento en este trabajo.
\end{abstract}

\section{Palabras claves}

Veracruz, San Juan de Ulúa, siglo XVI, huracanes, tormentas tropicales, siglo XVI, vulnerabilidad.

\begin{abstract}
Based on analysis of the consequences of hurricane in 1552 hit the city of Veracruz and the island of San Juan de Ulua, the author studies the vulnerability of the cities of the Spanish colonies, wondering how to assess the damage and to quantify its effects, and in general, how to study natural disasters from the Social Sciences. In this way, it refers to other natural phenomena such as cyclones and tropical storms, of which there are records in the Spanish cities. The study of the explanations from the religiosity of the people of those times and his insistence on leaving record of all events are analyzed in detail in this paper.
\end{abstract}

1.Doctor en Historia y Ciencias Humanísticas de la Universidad Pablo de Olavide de Sevilla, España; Maestro en Geografía Humana por parte de El Colegio de Michoacán y Licenciado en Historia por la Universidad Veracruzana, ambas en México. Email: paulonow@gmail.com 
76 El huracán que pasó por la ciudad de Veracruz y el puerto de San Juan de Ulúa, Nueva España 1552. La construcción de un "desastre" en la época virreinal. Paul César López Romero

\author{
Keywords: \\ Veracruz, San Juan de Ulua, hurricanes , tropical storms, XVI century, \\ vulnerability.
}

\title{
Introducción
}

El presente trabajo surgió como resultado de la colaboración del autor con el proyecto "Los Huracanes en la Historia de México. Memoria y Catalogo", del año 2011. En dicha propuesta de investigación (organizada por el Centro de Investigaciones y Estudios Sociales en Antropología Social) buscaba recabar, evaluar y clasificar información sobre los diversos fenómenos meteorológicos relacionados con los ciclones tropicales en México, incluyendo los dos océanos (Pacífico y Atlántico). El recuento y el rescate de información se realizaron desde el siglo XVI hasta nuestros días. Para llegar a buen fin se decidió organizar la búsqueda de información por regiones siendo la "Golfo de México" donde el autor de estas líneas colaboró.

En la búsqueda de información sobre ciclones y tormentas tropicales en los estados de Tamaulipas, Veracruz y Tabasco se identificaron diversas fuentes primarias. Se revisaron informes de autoridades, expedientes agrarios, cartografía y demás documentación en repositorios de carácter local, estatal, nacional e internacional. Un documento que resaltó de entre lo demás de la búsqueda fue el llamado "Información que se tomó sobre la tormenta que hubo en el puerto y la ciudad de Veracruz", documento conservado en el Archivo General de Indias en Sevilla, España. Este expediente sería el primero en la Historia documental de Nueva España, actualmente comprendido en el territorio del estado nacional mexicano, que marcaría la palabra "huracán" para referirse a un ciclón tropical. En otras referencias se habían acotado, borrasca, aguacero y/o ciclón, pero nunca la palabra derivada del "Kukulkan" (Dios de los vientos en el mundo Maya de Yucatán) que se plasma en este interesante expediente.

El paso de un Huracán es un fenómeno interesante pues en su trayecto por alguna población humana deja una serie de marcas y acciones en las personas. ¿Pero cómo evaluar sus daños? ¿Cómo clasificar sus efectos? Cuando un Huracán atraviesa una población deja diversos daños materiales y pérdidas humanas, sin embargo cuando pasa por lugares deshabitados ¿qué perjuicios deja? De ahí es imprescindible cuestionar cómo se considera y se asume un evento natural para las personas. No hace poco se tenía bien entendido que los huracanes, sismos, inundaciones eran eventos desastrosos que la naturaleza disponía sobre las localidades en todo el mundo. Una especie de "leviatán" fortuito que se encargaba de destruir un lugar y afectar a sus habitantes. Poco a poco se ha ido quitando esta noción para comprender que son las personas y las sociedades las que definen y construyen las condiciones de peligro antes, durante y después de un evento natural. Estas construcciones varían en tiempo y en forma, pero están 
presentes. La labor de los Historiadores en relación al estudio de estos eventos es observar y resaltar las diferencias en estas construcciones, y explicarlas.

Volviendo al caso que nos ocupa, el expediente sobre el "huracán" que azotó el entonces puerto de Veracruz y la Isla de San Juan de Ulúa bien puede demostrar cómo las sociedades valorizan un evento climático en su momento, cómo construyen las condiciones materiales que propician la noción de desastre y cómo se definen estrategias para enfrentar nuevamente los eventos naturales adversos. Esta parte es la más interesante pues puede demostrar que las sociedades negocian las condiciones adversas coyunturales por algún beneficio duradero. Ejercicio que nos permite también apreciar los tiempos cortos, medios y estructurales de la Historia, siendo las condiciones naturales las comprendidas en la tercera categoría.

Para el siglo XVI la entonces Nueva España contaba con una serie de instalaciones portuarias para la necesaria comunicación de las poblaciones continentales con las de Centroamérica, El Caribe y La Península. En la península de Yucatán ya funcionaba Campeche e Isla Mujeres, sin embargo un islote cerca de la costa occidental del actual Golfo de México funcionaría como el principal puerto para la Nueva España del siglo XVI. Las mercancías y colonos provenientes de Europa eran anclados cerca de este islote descubierto por Juan de Grijalva en 1518 y que era conocido como San Juan de Ulúa. En frente de ese islote y en buena parte de la costa mencionada era difícil acercar los barcos por el poco fondo que tenía el litoral. Por lo que las mercancías eran bajadas en la isla de Ulúa, y llevadas en lanchas hasta unos almacenes llamados "venta de Buitrón" para después ser conducidos por mulas a la ciudad de Veracruz, cuyo cabildo fue establecido por el conquistador Hernán Cortés en 1519, y de ahí comenzar el viaje al altiplano central del virreinato novohispano. El establecimiento de la ciudad veracruzana pasó por no pocas dificultades para llegar a ser lo que es. En primer lugar hay que tener presente que el sitio donde actualmente se encuentra dicho puerto no corresponde al de esta Historia, lo que nos indica los diversos esfuerzos por lidiar con las condiciones humanas y naturales para dar asentamiento fijo a una población. Estas dos localidades, la ciudad de Veracruz y la isla de San Juan de Ulúa, experimentaron un ciclón tropical en 1552.

El presente trabajo trata de hacer un breve ejercicio de lo mencionado sobre la construcción del desastre natural en una época y lugar específicos. Se hará mediante el análisis del expediente sobre el huracán que azotó la entonces ciudad de Veracruz en 1552. En primer lugar se realizarán una serie de anotaciones sobre los desastres naturales y su estudio en las ciencias sociales. Para después describir las condiciones materiales existentes en los sitios afectados por ese primer "huracán” documentado. Se revisarán los diversos esfuerzos por tener un establecimiento fijo para la ciudad de Veracruz a mediados del siglo XVI, así como las condiciones que el islote denominado San Juan de Ulúa mantuvo en la época. Para después anotar diversas características del expediente sobre el 
78 El huracán que pasó por la ciudad de Veracruz y el puerto de San Juan de Ulúa, Nueva España 1552. La construcción de un "desastre" en la época virreinal. Paul César López Romero

huracán y los elementos de construcción del desastre encontrados en el mismo. Todo esto para poder afirmar que las condiciones de desastre son construidas en el mismo seno de la sociedad que las experimenta.

\section{Los desastres naturales y su estudio en las ciencias sociales}

Durante la primera mitad del siglo XIX varios estudios sociales daban por sentado que un desastre (fenómeno peligroso) era producto de un agente natural, y que la sociedad impactada se constituía como una víctima al azar. De esta manera se afirmaba que un huracán simplemente pasaba sobre una localidad cualquiera dejando a su paso una serie de pérdidas materiales y humana. En ese sentido, los espacios y las sociedades eran siempre las víctimas de un evento fortuito e irracional, situaciones que las sociedades no podían eludir, ni resolver, sino sólo sufrir y aceptar el "destino".

Esa noción ha ido cambiando notoriamente en nuestros días. Actualmente se asume que los desastres han sido parte importante de determinadas sociedades a lo largo del tiempo. Muchos estudios tanto en Geografía como en Historia afirman que una sociedad crea, y es responsable, de las condiciones de peligro al rededor del espacio en el cual habita, al mismo tiempo que ésta define sus aspectos sociales, políticos, económicos e históricos. Es decir, anteriormente se le atribuía al medio natural la capacidad de amenazar al hombre, desligando a éste de su cierta responsabilidad en los eventos desastrosos. Pero hoy en día se asume que son las sociedades (tanto presentes como pasadas) las que realizan sus construcciones, las que sufren los daños materiales y humanos, y las que se organizan para buscar un remedio ante las amenazas "naturales". ${ }^{2}$

En el proyecto de investigación "Los Huracanes en la Historia de México. Memoria y Catálogo." estas nuevas premisas son seguidas para estudiar a las "amenazas" naturales. El programa registró históricamente la capacidad de los grupos sociales para organizarse (tanto material como socialmente) y lograr adaptarse al medio donde habita. Con lo cual se asume el protagonismo de las sociedades ante la naturaleza, ámbito que en décadas pasadas era impensable, es innegable. Esta afirmación se hace considerando que: a nivel local, y a partir de los constantes eventos peligrosos (como los huracanes), es donde los grupos sociales realizan una serie de adaptaciones con el objetivo de mejorar siempre la capacidad de sobrevivencia y protección de sus bienes y vidas; y de la misma forma son los grupos sociales que crean los factores de riesgo a cambio de otros beneficios materiales como comunicaciones y materias primas.

Teniendo en cuenta lo anterior, un estudio histórico sobre desastres también permite reconstruir historias locales, regionales y nacionales. Para logar esto, 
se deberá realizar un registro sistemático del qué, cuándo, dónde y cómo ocurrió determinado desastre. El documento presentado a continuación es una excelente fuente para cumplir con esta tarea. La "Información que se tomó sobre la tormenta que hubo en el puerto y la ciudad de Veracruz" contiene información cualitativa que permite realizar una serie de aproximaciones y estimaciones sobre cómo la sociedad de aquél tiempo enfrentó un huracán. Asimismo se ofrecen datos sobre cómo los veracruzanos de esa época definieron estrategias y adaptaciones antes, durante y después del evento.

No obstante para poder acercarse al establecimiento de los factores de riesgo en dicho documento es preciso conocer el contexto historio-espacial de las poblaciones aludidas en el documento. De esta manera, se expondrán una serie de apuntes sobre el emplazamiento que tuvo la ciudad de Veracruz y el puerto de San Juan de Ulúa durante la segunda mitad del siglo XVI. Para realizar estos apuntes recurriré al concepto geográfico de "emplazamiento", este reúne una serie de características en torno a la construcción de una ciudad. Aspectos necesarios para poder comprender también las señales del riesgo que se expusieron al momento del huracán del documento rescatado. El "emplazamiento" se refiere a una reunión del espacio sobre el que se asienta una localidad (con sus características fisiográficas) con la función dominante (defensiva, comercial, religiosa, política) ejercida por el mismo sitio en el momento de su fundación. De esta manera las ciudades tienen o pueden tener emplazamientos a lo largo de los cursos de los ríos, por el papel que estos accidentes han tenido en las comunicaciones, así como en la provisión de agua y materias primas. Siguiendo este concepto, el origen de los emplazamientos en la proximidad de un río responde a una función dominante en el origen de la ciudad, ligada a las actividades comerciales y al control de puntos estratégicos. ${ }^{3}$

\section{Sobre los emplazamientos de la ciudad de Veracruz (hoy La Antigua) y de San Juan de Ulúa, comunicación y comercio a cambio de riesgos}

La creación del ayuntamiento que serviría a la empresa de Hernán Cortés sobre las actuales tierras mexicanas propició el establecimiento de tres sitios con el toponímico "Veracruz" durante la primera mitad del siglo XVI. El establecimiento de dicho cuerpo político, que permitió a Cortes emprender su viaje al interior de la tierra incógnita que sería Nueva España, derivó en la búsqueda constante de un emplazamiento idóneo que permitiera: por un lado, mantener la residencia de la institución establecida, al servicio del gobierno español, y por otro, mantener la comunicación y el comercio con los dominios españoles en El Caribe, las Antillas y la Península. Un litoral costero, de cincuenta kilómetros de extensión, sería el espacio de varios experimentos y movimientos poblacionales para definir el lugar que albergara una sede política y un punto de comunicaciones para la naciente Nueva España. 
El primer sitio donde "Veracruz" tuvo un lugar fueron los arenales de Chalchicueyecan, a unos diecisiete kilómetros, al noroeste de la actual ciudad, en medio de grandes dunas de arena y selva tropical. Esta primera instalación fue sin duda de carácter provisional. Sólo sirvió para hacer la reunión de cabildo que le daba permiso a Cortés de internarse en el territorio sin tomar en cuenta al gobernador de Cuba y donde se desarmaron las naves del conquistador para que sus contrarios no regresaran a la isla. Al poco tiempo sus construcciones se limitaban a unas cuantas chozas pequeñas, construidas con estacas, lodo, palma y ramas de árboles, darían el aspecto de un rústico campamento militar. En el mismo año de 1519, y después de los encuentros con los habitantes indígenas de Cempoala y Quiahuiztlan, se decidió trasladar a la primitiva "Veracruz" hacia unos 40 kilómetros al noroeste. La nombrada "Villa Rica de la Veracruz" se fijó a una zona costera, donde existían varias elevaciones cercanas al mar, lagunas de agua dulce y varias "puntas", que bien podrían servir para instalaciones portuarias, además de esto la población estaba cercana a centros indígenas aliados (Cempoala y Quiahuiztlan). Para este nuevo emplazamiento es notoria la necesidad de establecer definitivamente al cabildo, el puerto, las fortalezas para su defensa, es decir, se buscaba que no fuera un mero campamento sino un poblado fijo. Los españoles, de esa época, solicitaron piedras y maderas a los pueblos indígenas cercanos, y se delimitaron los espacios para los nuevos edificios e infraestructura de la nueva población. Posteriormente, debido a la disminución de población indígena (por la mortandad de las epidemias introducidas) y el establecimiento del puerto de San Juan de Ulúa, varios kilómetros distantes de esta nueva villa, provocó un nuevo traslado, hacía la barra del río Huitzilapan (hoy referido como La Antigua) ${ }^{4}$ (Véase mapa 1.).

Mapa 1. Las diversas ubicaciones de Veracruz 1519-1550

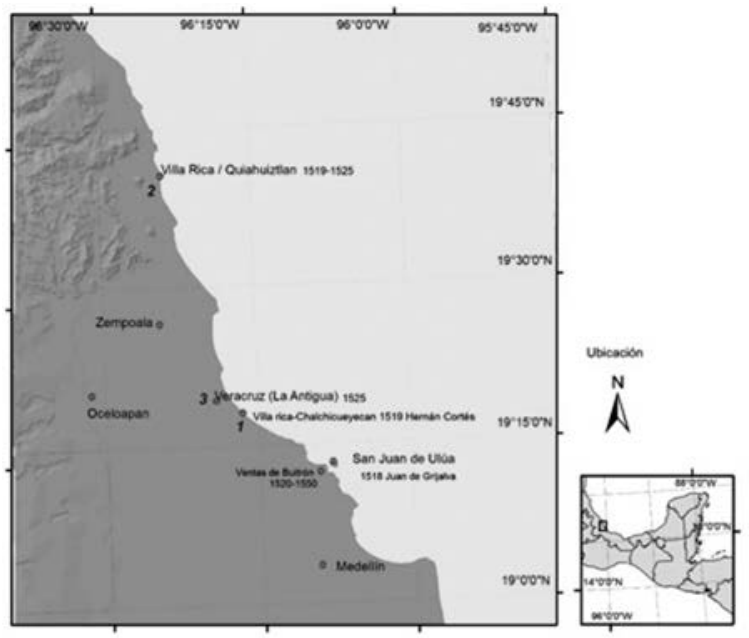

4. Para acercarse a los primeros emplazamientos de Veracruz, véase a: Acuña, 1981, Relaciones; Delgado, 1992, Cien, t. I; García, 1992, Puerto; Gonzáles, 2010, “Veracruz”; Trens, 1950, Historia, t. II. 
En 1525 la villa de Veracruz se hallaba establecida en los márgenes de un caudaloso río. Su establecimiento estaba enmarcado por un espacio ribereño, el cual contaba con varios árboles y vegetación selvática; asimismo la población estaba próxima a la recién fundada villa de Medellín y al puerto de San Juan de Ulúa. Al principio se planeaba que esta fundación de Veracruz serviría también de puerto, ya que se había atestiguado en anteriores expediciones que el río era navegable. No obstante esta primera impresión, con la práctica se verificó que la barra del dicho río terminó siendo un problema a sortear, su profundidad cambiaba de año en año a causa de las corrientes del río, las corrientes marítimas y los fuertes vientos que traían cantidades significativas de tierra y arena. Al final se decidió dejar la ciudad en dicho paraje y mantener el puerto en San Juan de Ulúa en el islote donde se había establecido, de todas formas la distancia entre los dos era mucho menor que en el anterior establecimiento. ${ }^{5}$

Para 1550 esta ciudad de Veracruz era una población estimable conformada por españoles, esclavos y muy pocos indios (sobrevivientes de las epidemias y congregados de las poblaciones de Cempoala y Quiahuiztlan). En dicha localidad se recogía todo lo venía de España para México y viceversa por medio de un sistema de flotas. Su espacio era descrito como una tierra calurosa, "enferma donde abundan los mosquitos donde se criaban pocos niños", la barra del río se consideraba mala por la variabilidad de su fondeadero. Sin embargo había ciertas ventajas: el río otorgaba abundante agua dulce, y "buenas y abundantes" pescas, especialmente de la especie conocida como "Bobo". Los grandes árboles y abundante vegetación cubrían con su sombra a las casas y calles, con lo que el calor era un tanto más soportable, asimismo había madera de sobra para la elaboración de casas, muebles y demás productos. La denominada ciudad de Veracruz contaba con una infraestructura notable: dos hospitales; una casa de contratación; varias edificaciones religiosas como un convento de franciscanos (en construcción), un convento de la compañía de Jesús, una iglesia del clero secular y una ermita, a las afueras de la población, dedicada a Santiago. Alrededor de una pequeña plaza estaban: el edificio de cabildo, varias casas, huertas y parcelas. Los "muros" de las construcciones estaban hechas de piedra, de canto de río, de canto de coral, de tapia y de adobe, y estaban techadas con teja, palmas y ramas de árboles. Cabe mencionar que algunas de las viviendas también servían de almacenes y posadas para el comercio. ${ }^{6}$

Al mismo tiempo, y durante el tiempo en que se buscó el sitio idílico para establecer a Veracruz con anterioridad, varios españoles se habían establecido en un islote conocido como San Juan de Ulúa. Ésta zona de tierra había sido registrada desde las primeras expediciones de Juan de Grijalva en las costas del sotavento veracruzano, y fue ocupada durante las primeras travesías de

5. Véase a Delgado, 1992, Cien, t. I; García, 1992, Puerto; Trens, 1950, Historia, t. II.

6. Véase la crónica de Antonio de Ciudad Real, "Tratado curioso y docto de las grandezas de NE", de 1584, en Delgado, 1992, Cien. T. 1, pp. 98-99. 
82 El huracán que pasó por la ciudad de Veracruz y el puerto de San Juan de Ulúa, Nueva España 1552. La construcción de un "desastre" en la época virreinal. Paul César López Romero

Cortes y sus soldados. Desde su ocupación definitiva en 1519 el sitio se convirtió rápidamente en un resguardo para las necesidades españolas de exploración y colonización, así como un punto de auxilio para las anteriores fundaciones de Veracruz (Chalchicueyecan, Quiahuiztlan). Durante el siglo XVI la isla fue muy valorizada de entre varios puntos costeros y ribereños, porque las naves de gran calado podían permanecer en un estrecho fondeadero que existía cerca del islote, sin correr el riesgo de encallar en la playa o en las bocas de los ríos cercanos.?

San Juan de Ulúa se convirtió en una población con características de puerto. A este interesante punto llegaban las embarcaciones con vinos, telas, aceites y demás productos de origen europeo y partían con los nuevos productos americanos. Al frente de la isla, en la costa, se encontraba una zona completamente llena de dunas de arena, que con el calor propio de la zona, hacían muy difícil (por ese momento) la construcción y delineación de una ciudad. Cabe mencionar que los barcos descargaban sus mercancías y de ahí éstas pasaban a la ciudad de Veracruz para su almacenaje. Para 1550 la isla contaba con una serie de anclas fijadas en su suelo, para que todas las naves se amarraran en época de vientos (julio-febrero); se había levantado una pequeña torre que funcionaba para observar las rutas de las embarcaciones y faro; existió una pequeña capilla, para los servicios eclesiásticos; una plaza central, y algunas casas tanto para las autoridades españolas como para esclavos. Las construcciones eran de madera, palma y lodo, y apenas se comenzaban a construir casas, y una torre, utilizando canto de coral y piedra. Al frente de la isla se habían construido unas edificaciones (conocidas como ventas de Buitrón) que ofrecían servicios de hospedaje y carruajes, a quienes se dirigían a la ciudad de Veracruz y al resto de los nuevos territorios españoles. ${ }^{8}$

Al término de estas breves descripciones de la antigua ciudad de Veracruz y del puerto de San Juan de Ulúa se observa tanto las características naturales como culturales que se fueron creando en sus emplazamientos. Los cuales fueron impulsados y arraigados en la fisiografía y el clima, sobre todo al buscar parajes cómodos y que brindaran recursos y materias primas; así como en las condiciones impuestas por la economía de colonización hispana, reflejada en la búsqueda de un paraje donde se establecieran edificaciones sólidas para el servicio de sus sociedades. Una vez definidos dichos emplazamientos, y a lo largo de la mencionada centuria, los habitantes de la ciudad y el puerto tuvieron que asumir los riesgos del medio y fueron construyendo las condiciones de riesgo, como la construcción de edificios de la ciudad de Veracruz en la ribera del río Huitzilapa, o el anclaje de embarcaciones en el estrecho fondeadero de Ulúa. Si bien los fuertes vientos y las crecientes de río que ocurrían a finales de año causaban daños, se ganaba el control del comercio y la comunicación entre la Península y sus nuevos territorios americanos.

7. Véase a Delgado, 1992, Cien, t. I; García, 1992, Puerto; Trens, 1950, Historia, t. II.

8. Véase la crónica de John Hawkings, "Tercero y penoso viaje que hizo el sr Jhon Hawking a las indias occidentales en 1567 y 1568, de 1564, en Delgado, 1992, Cien. T. 1, p. 59. 
Para mediados del siglo XVI, la ciudad de Veracruz comenzó a adquirir connotaciones de pueblo, y San Juan de Ulúa de puerto. A pesar del calor, los mosquitos y las amenazas latentes de inundación, se podían estacionar los botes y embarcaciones, y con ello, traer y llevar víveres provenientes de lugares distantes necesarios para las actividades de la nueva colonia. Esta negociación con el medio ribereño/costero permitió que en ambos sitios se crearan fuertes intereses económicos y sociales, y que al mismo tiempo ambos sitios estuvieran amenazados por algún viento proveniente del Atlántico, por un incremento en los niveles del río, o incluso por las epidemias causadas por el clima y la fauna tropical. Con este panorama ocurrió un Huracán el 2 de septiembre de 1552, evento que incidiría en las sociedades de estos dos emplazamientos para realizar cambios que terminaron por influenciar el devenir histórico de la ciudad y puerto de Veracruz actual.

\section{Sobre la "Información que se tomó sobre la tormenta que hubo en el puerto y la ciudad de Veracruz" del año de 1552}

El documento mencionado es un expediente localizado en el Archivo General de Indias, dentro del acervo documental Patronato (volumen 81, registro 25, fs. 954-965). Consta de 19 fojas y en éste se transcriben una serie de testimonios sobre el huracán ocurrido de los días 2 al 4 de septiembre de 1552 . El escrito comienza con un resumen de los hechos, realizado por el entonces alcalde mayor de Veracruz, García Escalante y Alvarado. Posteriormente se agregan los testimonios de once personajes. ${ }^{9}$ Los siete primeros narran lo ocurrido en la ciudad, y los siguientes cuatro comentan sobre su experiencia en la isla de San Juan de Ulúa.

El expediente recabado serviría para presentar las malas condiciones en que quedaron la ciudad y el puerto a las máximas autoridades españolas (virrey, Real Audiencia, Rey de España), así como las acciones que la sociedad, y sobre todo sus autoridades realizaron antes, durante y después del fenómeno descrito. Todo lo anterior con la firme intención de buscar fondos y disposiciones virreinales en el reparo de los daños. Aunque cabe señalar que en la información recabada hubo una preferencia, para buscar mejoras materiales, hacia el puerto de San Juan de Ulúa, en este sentido los testimonios indican en mayor medida los remedios para este sitio que para la ciudad de Veracruz.

9. Los testimonios sobre lo ocurrido en la ciudad de Veracruz fueron de: García de Escalante y Alvarado, alcalde mayor; Bartolomé Romero, párroco de la ciudad; Francisco de Rosales, vecino de la ciudad; Francisco de Torre médico y vecino de la ciudad; Martín Díaz de Segura, alcalde ordinario de la ciudad; Juan López "El Viejo", teniente de contador y vecino de la ciudad; Nicolás de Casana, genovés quien estaba de manera temporal en la ciudad, y Miguel de Arteaga, alcalde ordinario de la ciudad. Posteriormente están las crónicas de lo ocurrido en el puerto de San Juan de Ulúa de parte de Hernando de Vergara, receptor de la imposición; Diego Medel, Piloto de barco; Custodio Hernández, Piloto; Martín Camus, maestre. Archivo General de Indias, Real patronato, volumen 81, R.25, f. 954-965. 
84 El huracán que pasó por la ciudad de Veracruz y el puerto de San Juan de Ulúa, Nueva España 1552. La construcción de un "desastre" en la época virreinal. Paul César López Romero

Según el documento referido un fuerte viento de "huracán" azotó a los puntos mencionados, mientras se encontraban en "completa calma". Los fuertes vientos se registraron desde la tarde/noche del día viernes 2 de septiembre, hay un momento de "calma" en la mañana siguiente de sábado 3 , seguida de una "terrible" inundación y tormenta para toda la tarde/noche del día sábado y el domingo 4, afectando a las instalaciones de Veracruz sobre el río y San Juan de Ulúa en mar. En ambos lugares se registra que las pérdidas materiales fueron cuantiosas y lamentables; así como el derrumbe de casas y demás construcciones, y la merma de víveres, mercancías y embarcaciones, desde las más pequeñas hasta las más grandes. En cuanto a las pérdidas humanas, se informa el ahogamiento de varias personas, incluso su "desaparición" en el mar, así como se plasman diversas experiencias personales en los testimonios que bien pueden evidenciar impactos psicológicos.

Como se ha mencionado, el expediente da cuenta del papel que tuvieron las autoridades en el desarrollo del evento. Se narra cómo el alcalde mayor de Veracruz, junto con otros miembros del ayuntamiento, salen varias veces para vigilar los niveles del río, indicar a las personas del peligro que corría y con ayuda de pocos botes recatar a personas que se habían quedad encerradas o en los techos de sus casas. El uso de caballos fue significativo para no perder tiempo en la observación y dar la advertencia a los vecinos. Igualmente es interesante la manera en que se recaba la información en el expediente, aspecto que también habla de cómo la autoridad enfrentó el problema suscitado, desde la reunión de los testigos hasta la integración de sus impresiones en el expediente.

Las impresiones generadas por el huracán, y reunidas en este expediente, permiten conocer ciertas repercusiones psicológicas. En este sentido, se perciben dos tipos de impactos: individuales y colectivos, que bien pueden señalarse como traumas desde una perspectiva clínica. En cuanto al "trauma individual" se pueden apreciar varios impactos como el temor a la naturaleza, a Dios y los sentimientos de vulnerabilidad, en los siguientes ejemplos:

“[...] [el agua] rompió unos médanos de arena que estaban en medio del río de esta ciudad, que se los llevó todos; que aquellos quitar de allí no bastaría poder de príncipe cristiano, ni pagano, a quitarlos” [...]

“[...] Por unas veces hacía [el viento] un sonido tal que parecían voces de personas, y era gran temor por parecer [a la gente] que debían ser ángeles malos de los que quedaron al aire. [...]"

"[...] y todos daban voces pidiendo a Dios misericordia de las vidas, porque la dicha tormenta derrocó la mayor parte de las casas de la isla, y la venta la llevó con todos los que estaban dentro y los ahogó [...]"

“[...] que si la dicha corriente del dicho río viniera de noche, como vino de día, 
perecieran muchas personas de los vecinos, y estantes, y habitantes, de esta dicha ciudad; y asimismo cree este testigo que si el dicho río no se extendiera, como extendió, por las sabanas y llanos, en cantidad de cuatro o cinco leguas, anegara a toda esta ciudad sin que dejara casa en esta [...]"

De la misma manera se perciben ciertos traumas colectivos, es decir aquellos que golpean al tejido social y que impactan los lazos de la sociedad como: la identificación de un cambio en la vida cotidiana y en la forma de la ciudad.

“[...] Y tiene creído este testigo, que por estar el santísimo sacramento en la dicha iglesia no se acabó de perder toda la ciudad, y que Dios nuestro señor fue servido de castigarnos a todos [con] la pérdida de las haciendas y casas y dejarnos las vidas, para hacer penitencia de nuestros pecados. [...]”

“[...] Y que sabe [este testigo] que el pueblo queda perdido y azolvado en tal manera que, después de quedar arruinado mucha parte de él, quedan las casas muchas de ellas enterradas en lama hasta los cerros y otros más, por manera que quedan inhabitables muchas de ellas. [...]"

“[...] Y [siéndole] preguntado qué remedio le parece que se puede hacer para el remedio del puerto e isla; pues es cosa tan importante para el bien de esta Nueva España, dijo: Que le parece que se debe hacer una muralla de calicanto, para el reparo del dicho puerto, [en] todo lo que durase el espacio donde las Naos surgen, el cual conviene sea [construido] con brevedad. [...]"

O por el contrario se perciben ciertas identificaciones individuales con el grupo que sufrió la misma experiencia.

“[...] como vieron salir el río en tanta manera, salió [salieron] el alcalde mayor, y [los] alcaldes ordinarios, y [los] regidores, [y] andaban por toda la ciudad avisando a los vecinos y moradores de ella que se pusiesen en cobro, y [se] llevasen lo que tenían a los medanos, porque el río iba creciendo.[...]”

“[...] Y era muy grande lástima de ver a las mujeres y a los niños, ponerse por las dichas casas y por encima de ellas, llorando y dando gritos pidiendo misericordia a Dios, [para] que los librase de tan gran tormenta y de muerte tan desastrosa [...]"

“[...] Muchos hubo que fueron parte de salvación de muchas personas que tuvieron necesidad de socorro, especialmente el alcalde Martín Díaz, que desde la mañana [del viernes] hasta otro [el] día que quebró el río, que se podía navegar, nunca desamparó la ciudad, [y éste estuvo] socorriendo muchos enfermos que no tenían otro remedio, y otra gente pobre. [...]" 
“[...] Y que pasada la dicha tormenta este testigo salió [de San Juan de Ulúa] atrás a servir y a remediar a esta ciudad [de Veracruz] [...]".

Para finalizar este apartado bien se pueden poner algunas implicaciones de dicho evento a largo plazo, las cuales pueden seguirse a través de la bibliografía y las fuentes primarias. Para el año de 1609, cincuenta años después de ocurrido el huracán, la ciudad de Veracruz se volvió a trasladar. En esta ocasión en los arenales que estaban enfrente de San Juan de Ulúa. Esta "ciudad de tablas" o "Nueva Veracruz" se trazó y estableció para establecer una mejor población para el beneficio de los viajeros, embarcaciones y víveres provenientes de Europa, que iba incrementándose año con año. Mientras tanto se registraba que la antigua ciudad de Veracruz (conocida ya como Veracruz vieja) estaba semi-desierta y en pobreza. Las casas estaban arruinadas, que era una lástima, "porque antes fueron muy buenas". ${ }^{10}$ Se narraba que en dicha localidad sólo habían permanecido algunos españoles junto con un alcalde mayor, que estaba a cargo de una nueva jurisdicción ${ }^{11}$ y que el acopio de bastimentos y víveres era escaso. De esta manera la pequeña población se mantenía sólo por la nueva jurisdicción encargada y por quienes no quisieron partir a la nueva Veracruz. Un tanto convencidos, por el arraigo de los años, de que el lugar todavía podía garantizar comodidad y supervivencia.

La solicitud del remedio para San Juan de Ulúa, punto interesante para el comercio y la comunicación entre las Españas, tuvo lugar en 1570, cuando fue aprobado un proyecto de reconstrucción del puerto. En este plan se incluían: la construcción de un grueso muro de piedra y coral que protegería la zona sur-oeste de la isla, y de donde se amarrarían las naves que estuvieran en el fondeadero de la isla; dos torres de dimensiones importantes para la vigilancia de los vientos y naves; instalaciones para armamento y artillería; y casas de piedra para las habitaciones de los oficiales y autoridades residentes del puerto. (véase figura 1).

\section{Conclusiones generales}

El caso del huracán ocurrido en Veracruz entre el 2 y el 4 de septiembre de 1552 es un claro ejemplo sobre las diversas acciones realizadas por una sociedad antes, durante y después de un evento natural adverso. La primera acción ocurrió después del huracán: dejar constancia documental de las situaciones experimentadas por los pobladores. Mismas que buscaron obtener un remedio a las pérdidas materiales ocurridas, pero no para dejar definitivamente el lugar o para cambiarlo de manera radical. En el expediente escrito, sin tener en cuenta su objetivo primordial, se pueden revisar las acciones coyunturales

10. Véase la crónica de Alonso de la Mota y Escobar, “memoriales”, de 1609 en Delgado, 1992, Cien. T. 1, p. 165.

11. Jurisdicción conocida como Veracruz vieja. Véase a Gerhard, 1992, Geografía. 
aunadas a los eventos meteorológicos que en conjunto con un análisis histórico del emplazamiento veracruzano permite describir las acciones anteriores al desastre. Al término de este breve análisis se puede ver que una serie de condiciones comerciales dejaron los puntos con varios habitantes dedicados al comercio, y asimismo una serie de instalaciones donde se resguardaban mercancías de diversa índole. Es imposible que los habitantes no conocieran las situaciones adversas de sus localidades, años antes ya se habían experimentado en la mudanza de la ciudad de Veracruz, el clima, la población y la necesidad de tener puntos para el comercio y la política local asentó a los lugareños en un sitio que implicaría inundaciones y azote de vientos. Cuando el huracán ocurrió las características urbanas y comerciales se encontraban (después de veinticinco años de su establecimiento) en plena consolidación. Es por eso que el desastre tuvo varios impactos, el perder las mercancías y las casas construidas son motivo de lamentación en todo el expediente. Asimismo se hace referencia a situaciones religiosas como forma de explicación, una muestra de la cultura religiosa novohispana. Esta sociedad tenía bien fincados sus fines espirituales, al buscar la salvación de ornamentos de iglesia y del prójimo. Sin duda esta experiencia marcó a los habitantes de la antigua ciudad de Veracruz per las actividades comerciales no se mudaron del lugar, sino que al contrario se mantuvieron por otros años más y se pidió financiamiento para poder construir un mejor sitio, preparado para futuros eventos, tanto los normales como los extremos.

Figura 1. Mapa de San Juan de Ulúa en 1590.

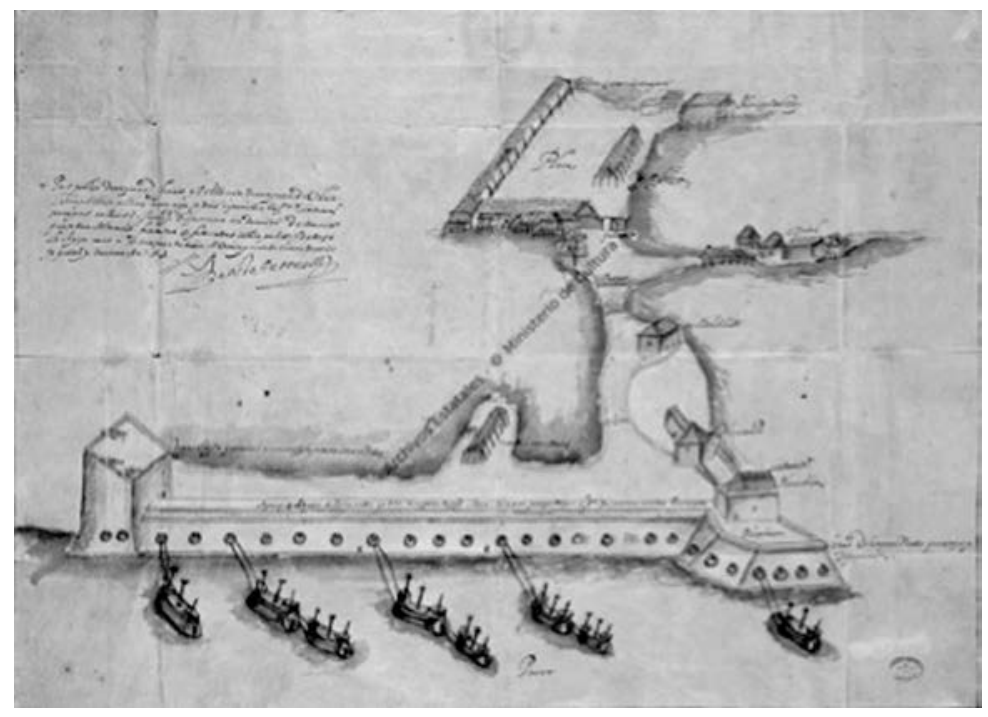

En esta figura se puede apreciar el estado de San Juan de Ulúa a finales del siglo XVI, y se observa que se ha construido la muralla y las torres que se solicitan en el documento presentado. Referencia Archivo General de Indias, Mapas y Planos, México, 36, año 1590. 


\section{Bibliografía}

Acuña, René. (Ed.) Relaciones geográficas del s. XVI: Tlaxcala. Tomo II, México, Universidad Nacional Autónoma de México, 560 pp. 1981.

Delgado, Ana María(coord.) Cien viajeros en Veracruz crónicas y relatos, Xalapa, Veracruz, Gobierno del Estado de Veracruz, 12 tomos. 1992.

Escobar Ohmstede, Antonio. Desastres agrícolas en México. Catálogo histórico (siglo XIX), Fondo de Cultura Económica/CIESAS, México, D.F. 2004.

García Acosta, Virginia. "La perspectiva histórica en la Antropología del riesgo y del desastre. Acercamientos metodológicos”, en: Relaciones. Estudios de historia y sociedad (Religiosidad y desastres), XXV (97): 123-142. 2004.

García Acosta, Virginia, y Lozoya Padilla, Raymundo. Proyecto “Los Huracanes en la Historia de México. Memoria y Catálogo", protocolo de la propuesta de investigación, México, Centro de Investigación e Estudios Superiores en Antropología Social, Universidad de Colima, 26 pp. 2007.

García Díaz, BernardoPuerto de Veracruz, Serie: Veracruz: imágenes de su historia, No. 8, México, Archivo General del Estado de Veracruz, 383 pp. 1992.

Gonzáles, Joaquín. “Veracruz. Perfiles regionales, económicos y poblacionales”, artículo para el libro Historia general de Veracruz, actualmente en proceso de edición por parte de la Universidad Veracruzana, el Gobierno del Estado de Veracruz y la Comisión del Estado de Veracruz para la conmemoración de la Independencia Nacional y la Revolución Mexicana. 2010.

Padilla Lozoya, Raymundo. El huracán del 59. Historia del desastre y reconstrucción de Minatitlan, Colima, Mexico, Universidad de Colima, H. Ayuntamiento de Minatitlán, 180 pp. 2006.

Trens, Manuel B. Historia de Veracruz, Xalapa, Veracruz, Gobierno del Estado de Veracruz, 6 tomos. 1950. 